\title{
Broad vs. narrow focus in Greek
}

Stella Gryllia

LUCL, Leiden University, The Netherlands

https://doi.org/10.36505/ExLing-2006/01/0030/000030

\begin{abstract}
This paper reports the results of a production and a perception experiment about focus in Greek.
\end{abstract}

\section{Introduction}

Let's look at the example in (1).

O Kostis kerdise to lahio.

the-NOM Kostis-NOM win-3SG the-ACC lottery-ACC

'Kostis won the lottery.'

The word order SVO (ex.1) is a felicitous answer to an all focus question, 'What's up?', a verb phrase focus question, 'What did $S$ do?' and a object focus question, 'What $V S$ ?'. Thus, example (1) is multiply ambiguous and its focus breadth varies. The focus' breadth depending on the preceding question varies among $[\mathrm{SVO}]_{\mathrm{F}} \mathrm{S}[\mathrm{VO}]_{\mathrm{F}}$ and $\mathrm{SV}[\mathrm{O}]_{\mathrm{F}}$. The focus' breadth $[\mathrm{SVO}]_{\mathrm{F}}$ can be described as broad, whereas $\mathrm{SV}[\mathrm{O}]_{\mathrm{F}}$ as narrow. However, broad and narrow focus are relative terms. Verb phrase focus $\mathrm{S}[\mathrm{VO}]_{\mathrm{F}}$ is broad compared to $\mathrm{SV}[\mathrm{O}]_{\mathrm{F}}$ and narrow compared to $[\mathrm{SVO}]_{\mathrm{F}}$. Narrow focus has often been associated with contrastive interpretation. In this paper, following Cohan (2000), the terms broad and narrow focus are taken to refer to the breadth of focus.

A question that emerges is whether the breadth of focus is reflected on the phonetic realization of the utterances. More specifically, do speakers produce a difference among sentence focus, verb phrase focus and object focus? Do listeners perceive any difference? To tackle these questions, a production and a perception experiment were performed.

\section{Production experiment}

In GrToBI, Arvaniti \& Baltazani (2000) reported that narrow focus is signaled by a $\mathrm{L}+\mathrm{H}^{*}$ nuclear accent, whereas broad focus by a $\mathrm{H}^{*}$ nuclear accent. We thus expect to find a difference among the three types of focus.

\section{Methods}

Stimuli. A list of 13 sets of four question-answer (QA) pairs was constructed. For the first three QA pairs, the word order of the answer was kept constant, it

ExLing 2006: Proceedings of 1st Tutorial and Research Workshop on Experimental Linguistics, 28-30 August 2006, Athens, Greece 
was namely SVO, whereas the question varied. There were three types of questions: an all focus (2a), a verb phrase focus (2b) and an object focus (2c). In the fourth QA pair the question was an object focus question (2d) and the word order of the answer was OVS. A sample is given in (2).

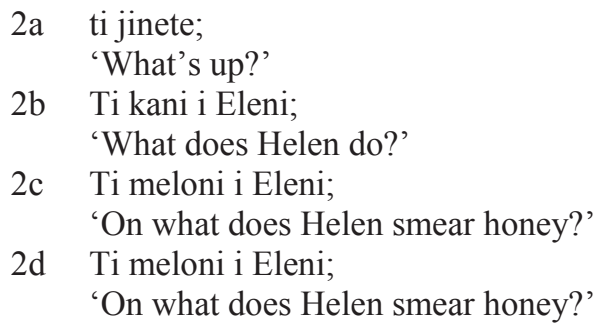

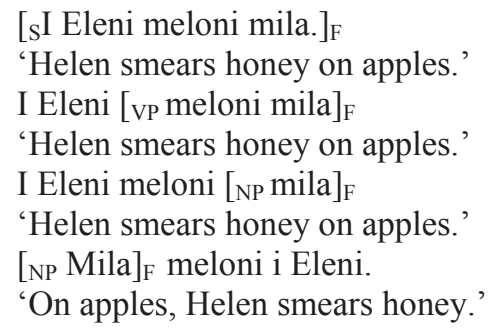

Procedure. A self-paced stimulus presentation was used. Utterances were directly recorded via a head-mounted close-taking microphone (Shure SM10A) on computer disk using an Abode Audition Software. Forty native speakers of Athenian Greek participated in the experiment.

\section{Analysis}

Four sets out of the total 13 were analyzed. The productions of all 40 participants (640 utterances) were analyzed, using Praat. The autocorrelation pitch extraction method (Boersma 1993) was used to determine the fundamental frequency (F0) as the primary correlate of vocal pitch. All F0 curves in the materials were stylized in this way. Afterwards, pivot points were defined. For each utterance, ten pairs of time points and their correspondent pitch $\left(t_{1}\right.$, $\left.p_{1} \ldots t_{10}, p_{10}\right)$ were obtained. The time-frequency coordinates of the pivot points were automatically extracted and stored in a database for off-line statistical processing. Thereafter, one-way analyses of variances were performed. The independent variable was the type of focus. The dependent variable was the frequency of one specific pivot point. Ten one-way analyses of variance were run, one for each of the ten pivot points.

\section{Results}

Comparing the results of ten different one-way ANOVAs for four types of focus with the results of ten different one-way ANOVAs for three types of focus, excluding the cases of preverbal object focus, it can be concluded that speakers do not produce any significant differences with respect to sentence focus, verb phrase focus and postverbal object focus. The difference $\Delta$ between $\mathrm{p}_{3}$ (pitch peak on the first content word) and $\mathrm{p}_{6}$ (pitch peak on the second content word) was established. $\Delta$ corresponds to the downstep in pitch between $p_{3}$ and $p_{6} .160$ accentual downsteps per focus type were obtained, stored in a database for off-line statistical processing and compared by per- 
forming paired t-tests. The downstep in sentence focus differs significantly from the downstep in verb phrase focus. The same holds for the downstep in $\left.{ }_{\mathrm{S}} \mathrm{SVO}\right]_{\mathrm{F}}$ and $\mathrm{SV}\left[{ }_{\mathrm{NP}} \mathrm{O}\right]_{\mathrm{F}}$. The downstep in verb phrase focus differs significantly from preverbal object focus. The same holds for the downstep in postverbal object focus and preverbal object focus. It should be noted that the downstep in verb phrase focus does not differ from the downstep in postverbal object focus. The size of the accentual downstep was also analyzed as a function of the four focus types per gender. The accentual downstep in $\left[{ }_{\mathrm{NP}} \mathrm{O}\right]_{\mathrm{F}} \mathrm{VS}$ is large, namely $22 \mathrm{~Hz}$ by females and $25 \mathrm{~Hz}$ by males. In contrast to the large downstep in preverbal object focus, the accentual downstep in $\mathrm{S}\left[{ }_{\mathrm{VP}} \mathrm{VO}\right]_{\mathrm{F}}$ is small, $6 \mathrm{~Hz}$ by females and $7.4 \mathrm{~Hz}$ by males. Female and male speakers differ with respect to the accentual downstep in $\left.{ }_{\mathrm{S}} \mathrm{SVO}\right]_{\mathrm{F}}$ and $\mathrm{SV}\left[{ }_{\mathrm{NP}} \mathrm{O}\right]_{\mathrm{F}}$. In $\left[{ }_{\mathrm{S}} \mathrm{SVO}\right]_{\mathrm{F}}$ the female speakers downstep by $26 \mathrm{~Hz}$, whereas the male speakers by $7 \mathrm{~Hz}$. In $\mathrm{SV}\left[{ }_{\mathrm{NP}} \mathrm{O}\right]_{\mathrm{F}}$ the female speakers downstep by $15 \mathrm{~Hz}$, whereas the male speakers' downstep is $0 \mathrm{~Hz}$. Four ANOVAs were run to evaluate the differences between male and female speakers. The independent variable was gender. The dependent variable was the accentual downstep. Female and male speakers differ significantly with respect to the accentual downstep in $\left.{ }_{\mathrm{S}} \mathrm{SVO}\right]_{\mathrm{F}}$. The difference in accentual downstep between female and male speakers in $\mathrm{SV}\left[{ }_{\mathrm{NP}} \mathrm{O}\right]_{\mathrm{F}}$ is marginally significant.

Perception experiment

\section{Methods}

Stimuli. 24 stimuli produced by a male and a female speaker, who participated in the production experiment were used. The set of twelve stimuli was the same for the male and the female speaker. These twelve stimuli consisted of four sets of three sentences: $\left.{ }_{\mathrm{S}} \mathrm{SVO}\right]_{\mathrm{F}}, \mathrm{S}[\mathrm{VP} V \mathrm{~V}]_{\mathrm{F}}, \mathrm{SV}\left[_{\mathrm{NP}} \mathrm{O}\right]_{\mathrm{F}}$.

Procedure. The 24 stimuli were made audible with a fixed interstimulus interval of $0.3 \mathrm{sec}$ (offset-onset). Listeners were supplied with an answering sheet containing a list of questions in sets of three. Each set contained a sentence focus, a verb phrase focus and an object focus question. Listeners were instructed to tick off the question which according to them corresponded best to the declarative sentence they were listening to. Forty native speakers of Greek, twenty females and twenty males participated in the experiment. These forty speakers had not participated in the production experiment.

\section{Results}

960 responses were analyzed. Listeners seem to perceive some differences among the types of focus. Sentence focus is perceived below chance level, verb phrase focus is perceived just above chance level, while postverbal object focus is perceived well above chance level. More specifically, when the focus intended by the speakers was sentence focus, then $14.1 \%$ perceived it as such. When the intended focus was verb phrase focus, it was correctly 
perceived by $42.2 \%$ of the listeners. When the intended focus was postverbal object focus, $74.7 \%$ of the listeners perceived it correctly. The distribution of responses differs significantly across focus types also in terms of incorrect responses. When the intended focus type is postverbal object focus, then sentence focus is hardly ever chosen as a response. However, when the intended focus type is verb phrase focus, then the distribution of responses is much more balanced. More specifically, out of 960 utterances, sentence focus was chosen as a response 80 times, i.e. $8.3 \%$, while verb phrase focus was chosen as a response 304 time, i.e. $31.7 \%$ and postverbal object focus was chosen as a response 576 times, i.e. $60 \%$. These results show that there is a preference for choosing postverbal object focus as an answer and a dispreference for sentence for sentence focus. This preference and dispreference might be interpreted as a response bias. However, the preference for postverbal object focus might not be related to the acoustic properties of the stimuli. Crain et al. (1994) have experimentally shown that adults follow the least effort strategy for ambiguity resolution, reducing the risk of making commitments that will need to be changed later. In this sense, the dispreference for sentence focus is not so surprising. When sentence focus is selected as a response, then it coincides with the focus intended by the speaker at $14.1 \%$. This percentage is almost double than the incorrect response verb phrase focus $(7.2 \%)$. When verb phrase focus is selected as a response, then it coincides with the focus intended by the speaker at $74.7 \%$. This is $20 \%$ higher than the incorrect response sentence focus.

\section{Acknowledgements}

Special thanks to Vincent van Heuven. I wish to acknowledge Lingua, Elsevier and LUF for financial support. Parts of the production experiment will appear in Proceedings of CamLing 2006.

\section{References}

Arvaniti, A. and Baltazani, M.. 2000. GREEK TOBI: A System for the Annotation of Greek Speech Corpora. In Proceedings of 2nd International Conference on Language Resources and Evaluation Vol. 2: 555-62.

Boersma, P. 2003. Accurate short-term analysis of the fundamental frequency and the harmonics-tonoise ratio of a sampled sound. In IFA Proceedings 17: 97-110.

Boersma, P. and Weenink D. 2005. Praat: doing phonetics by computer.

Cohan, J. 2000. The Realzation and Function of Focus in Spoken English. PhD dissertation, University of Texas.

Crain, S.W.Ni, and Conway, L. 1994 Learning, parsing and modularity. In C. Clifton, L. Frazier and K. Rayner (eds.) Perspectives on sentence processing. Lawrence Erlbaum: 443-467. 